\title{
Prefácio
}

\section{Avanços na pesquisa e no desenvolvimento da aquicultura brasileira}

\author{
Carlos Magno Campos da Rocha(1), Emiko Kawakami de Resende ${ }^{(2)}$, \\ Eric Arthur Bastos Routledge ${ }^{(1)}$ e Lícia Maria Lundstedt(1)
}

\begin{abstract}
(1)Embrapa Pesca e Aquicultura, QD 104 Sul, Avenida LO1, no 34, Conj. 4, 1 e 2o Pavimentos, Plano Diretor Sul, CEP 77020-020 Palmas, TO. E-mail: carlos.magno@embrapa.br, eric.routledge@embrapa.br, licia.lundstedt@embrapa.br (2)Embrapa Pantanal, Rua 21 de Setembro, no 1.880, Bairro Nossa Senhora de Fátima, Caixa Postal 109, CEP 79320900 Corumbá, MS. E-mail: emiko.resende@embrapa.br
\end{abstract}

O mercado global de alimentos tem experimentado expansão sem precedentes e mudança nos padrões alimentares, tornando-se mais homogêneo e globalizado. Em 2013, as previsões do consumo de pescados aproximam-se de $20 \mathrm{~kg}$ por habitante por ano, com produção estimada de mais de 160 milhões de toneladas (Food and Agriculture Organization of the United Nations, 2013). Além disso, a demanda por produtos à base de pescado deve aumentar nas próximas décadas, seja por razões socioeconômicas, de saúde ou religiosas. Essa tendência vem sendo observada e, atualmente, quase metade da produção de pescado já é originada da aquicultura. Assim, o aumento do consumo per capita de pescado será cada vez mais dependente da disponibilidade dos produtos da aquicultura e sua capacidade de adequação às exigências do mercado consumidor.

O Brasil tem grande potencial para a aquicultura, pelas condições naturais, pelo clima favorável e pela sua matriz energética. Este potencial está relacionado à sua extensão costeira de mais de oito mil quilômetros, à sua zona econômica exclusiva (ZEE) de 3,5 milhões de $\mathrm{km}^{2}$ e à sua dimensão territorial, que dispõe de, aproximadamente, $13 \%$ da água doce renovável do planeta. Em relação às águas continentais, fazem parte desse volume as áreas alagadas artificialmente pela construção de barragens, contidas em reservatórios de usinas hidrelétricas, bem como áreas particulares para produção em viveiros de terra escavados. Entre elas, destaca-se a possibilidade de utilização das águas da União, tanto as de reservatórios de hidrelétricas, como as de estuários para a instalação de parques aquícolas. O marco legal que autoriza a utilização das águas da União, para fins de aquicultura, foi estabelecido em até $1 \%$ da área ou à capacidade de suporte do rio/lago/ estuário (o menor dos dois critérios). Mas, mesmo com tantos atributos favoráveis, o Brasil ainda possui muitas condições para desenvolver seu potencial produtivo para a aquicultura.

Fatos que normalmente são considerados extremamente positivos, tais como a dimensão continental do território brasileiro, a diversidade de biomas e a imensa biodiversidade, que abriga inúmeras espécies com potencial zootécnico, criam um cenário bastante complexo e podem pulverizar ações que, se não organizadas, podem comprometer ou atrasar $\mathrm{o}$ desenvolvimento da cadeia produtiva da aquicultura no país. Os investimentos em pesquisa, desenvolvimento e inovação são fundamentais para elevar o patamar tecnológico e favorecer a competitividade e a sustentabilidade da aquicultura brasileira.

O pescado é a carne mais demandada mundialmente (Sidonio et al., 2012) e a de maior valor de mercado. Porém, no Brasil, seu consumo ainda é baixo, mesmo tendo aumentado nos últimos anos para $11,17 \mathrm{~kg}$ por habitante por ano (Brasil, 2013), valor ainda abaixo do mínimo recomendado pela Organização Mundial de Saúde, que é de $12 \mathrm{~kg}$ por habitante por ano (Food and Agriculture Organization of the United Nations, 2012), mas $14,5 \%$ a mais do que em relação ao ano anterior (Brasil, 2010).

Embora o consumo nacional ainda seja baixo, a balança comercial nacional de pescado encontra-se em deficit desde 2006, tanto em valores monetários quanto em volume comercializado. Segundo dados estimados pelo Ministério da Pesca e Aquicultura (MPA), em 2011, a importação de pescado e subprodutos atingiu US\$ $1.262 .888 .212(349.529 .158 \quad \mathrm{~kg})$, enquanto a exportação do produto nacional atingiu apenas US\$ $271.193 .147(42.263 .415 \mathrm{~kg})$, o que representa deficit de aproximadamente US\$991 milhões $(307.265 .743 \mathrm{~kg})$ e elevação de $32,5 \%$, em relação ao deficit computado em 2010, que era de aproximadamente US\$ 748 milhões (Brasil, 2011). 
Esses dados apontam que parte do consumo nacional vem sendo amplamente suprida por meio de importações de pescados. Infelizmente, parte dessa exigência do mercado não pode ser suprida por produtos nacionais, como no caso do bacalhau e do salmão. Essas são espécies exóticas, e os custos de produção seriam economicamente inviáveis em condições tropicais. No entanto, há muitas espécies promissoras no país, tanto para atender aquelas empresas que optarem por estratégias de custo, deslocando importações asiáticas e argentinas de espécies de peixes de custos mais acessíveis, quanto para aquelas que optarem por estratégias de diferenciação e apostarem nas espécies nativas de ampla aceitação (Sidonio et al., 2012).

Diante da crescente importância no cenário mundial e nacional, a aquicultura passou a ser considerada estratégica para o Governo Brasileiro. Assim, em 2003, de um pequeno departamento ligado ao Minsitério da Agricultura, Pecuária e Abastecimento, foi criada a Secretaria Especial de Aquicultura e Pesca da Presidência da República (Seap/PR), transformada, em 2009, em Ministério da Pesca e Aquicultura (MPA). O MPA é responsável pela implantação e desenvolvimento da política nacional pesqueira e aquícola, o que fez com que o setor produtivo recebesse mais atenção e, assim, foi estabelecido um marco de governança adequado às suas necessidades.

A Empresa Brasileira de Pesquisa Agropecuária (Embrapa), atenta a esse movimento de diversificação da economia brasileira, realizou um mapeamento das principais competências capazes de contribuir para o desenvolvimento da aquicultura no Brasil. A empresa identificou que, além das instituições de ensino, ciência e tecnologia e das equipes de Aquicultura e Pesca, distribuídas em 15 centros da Embrapa pelo Brasil, seria necessária a criação de um centro de referência em pesquisa, desenvolvimento e transferência de tecnologias nessa temática. E com o apoio do MPA, criou em agosto de 2009 a "Embrapa Pesca e Aquicultura", na cidade de Palmas, TO, com o propósito de coordenar as iniciativas de pesquisa na instituição e operar como um centro de referência na geração de tecnologias para aquicultura e pesca. Consequentemente, o tema se estabeleceu como pauta obrigatória na empresa, e as equipes passaram a trabalhar integradas por projetos de pesquisa em rede.

Antes mesmo da criação do centro temático, a Embrapa executava ações de pesquisa na área, em que se destaca o Projeto "Bases Tecnológicas para o Desenvolvimento Sustentável da Aquicultura no Brasil - Aquabrasil", iniciado em 2008, que teve como objetivo promover um salto tecnológico da aquicultura brasileira. Para tanto, o projeto foi estruturado em formato de rede e congregou 16 unidades da Embrapa, 26 universidades e instituições de pesquisa, oito empresas privadas, três empresas estaduais e dezenas de pessoas entre pesquisadores, professores, alunos e demais colaboradores. OMPA, além do aporte financeiro substancial, viabilizado por meio de parceria com o Conselho Nacional de Desenvolvimento Científico e Tecnológico (CNPq), foi um importante parceiro na definição do foco de atuação e no acompanhamento do Projeto. O Aquabrasil, coordenado pela Embrapa, foi um marco na aquicultura brasileira, tanto pela sinergia de ações quanto pela abrangência dos resultados.

Diante de tamanha importância, a Embrapa iniciou uma articulação institucional, para lançar o número temático de Aquicultura, na revista Pesquisa Agropecuária Brasileira (PAB). O esforço com os demais Centros da Embrapa e instituições de pesquisa e ensino do país materializa-se, em 2013, com o lançamento deste número temático, que representa um marco inédito para a comunidade técnico-científica atuante na área e, juntamente com a comemoração dos 40 anos da Embrapa, reforça seu papel no desenvolvimento do agronegócio brasileiro.

Dos 57 trabalhos publicados, 41 são artigos completos e 16 são notas científicas. Estes trabalhos procederam de 55 diferentes instituições públicas e privadas de pesquisa, ensino e tecnologia, e abrangem as diferentes áreas temáticas da aquicultura. A diversidade de instituições e autores, representada neste volume temático, forma uma nova base para a composição de futuras redes de pesquisa e eleva a possibilidade de acordos de cooperação que podem contribuir para o preenchimento de lacunas técnico-científicas e aprimoramento do setor.

A maior parte dos trabalhos aborda aspectos da nutrição, tais como índices de desempenho zootécnico e manejo nutricional, digestibilidade de ingredientes, exigências nutricionais, aspectos do metabolismo nutricional e a relação entre nutrição e sanidade, com a avaliação e o desenvolvimento de prebióticos, probióticos e simbióticos. Outro grupo representativo de trabalhos tem foco nos aspectos do manejo produtivo, avalia a densidade de estocagem, o manejo 
na larvicultura e diferentes abordagens para minimizar as diversas formas de estresse que acometem os animais em condições típicas de cultivo e confinamento. Além dos aspectos anteriormente citados, os trabalhos de sanidade englobam aspectos parasitológicos e avaliam as condições de higidez do pescado em diferentes fases de crescimento e condições de cultivo.

Dos dois trabalhos em melhoramento genético, um correlaciona a herdabilidade à velocidade de crescimento, em tilápias da linhagem GIFT ("genetic improvement of farmed tilapia"), e o outro estima a variabilidade genética em reprodutores brasileiros de camarão (Litopenaeus vannamei). Os trabalhos com foco em reprodução relacionam respostas fisiológicas ao manejo reprodutivo, características morfológicas das gônadas e a viabilidade de embriões criopreservados. Os aspectos ambientais são extremamente importantes e devem receber especial atenção, para garantir a sustentabilidade ambiental da aquicultura. Além desses, alguns trabalhos enfocam o processamento e o aproveitamento integral, a utilização de subprodutos, bem como a higidez, formas de conservação e o tempo de prateleira do pescado. Finalmente, mas não menos importantes, são referidos os trabalhos que envolvem etologia e bem estar animal, temática de constante e crescente desafio na aquicultura.

Os trabalhos publicados neste número têm como objeto de estudo 29 espécies diferentes e três combinações de peixes híbridos de interesse para a aquicultura. Entre elas, 18 espécies de peixes de água doce e quatro marinhas, uma espécie de camarão marinho (Litopenaeus vannamei) e duas de água doce (Macrobrachium amazonicum e $M$. rosenbergii), uma de molusco bivalve (Crassostrea gasar), uma de anfíbio (rã-touro, Lithobates catesbeianus), uma de microalga (Haematococcus pluvialis) e uma de caranguejo (Ucides cordatus). Todas essas espécies são representativas das diferentes regiões fisiogeográficas e exprimem o potencial e os desafios a serem enfrentados no setor.

Além disso, os artigos buscam, de forma direta ou indireta, promover o incremento tecnológico, melhorar a qualidade dos métodos de manejo e dos processos, e tornar disponível o conhecimento científico relacionado à aquicultura. Adicionalmente, seus impactos serão positivos também em outros segmentos, já que pesquisa, desenvolvimento e inovação podem traduzirse em produtos e serviços tecnológicos diretamente aplicados.

Os trabalhos publicados neste volume da revista Pesquisa Agropecuária Brasileira poderão, ainda, contribuir para discussões que permeiam o Portfólio de Aquicultura, novo formato de organização da programação técnica da Embrapa, cujo objetivo é priorizar o apoio a projetos de pesquisa para a geração de conhecimentos e tecnologias, por meio de projetos e ações com foco temático relacionado. Além disso, objetivam disseminar informação e conhecimento que poderão ser adotados por diferentes instituições, contribuindo para o fortalecimento da comunidade científica, com aplicações para o setor produtivo, para que possa promover o avanço do setor aquícola como um componente importante do agronegócio nacional.

\section{Referências}

BRASIL. Ministério da Pesca e Aquicultura. Boletim estatístico da pesca e aquicultura: Brasil 2010. Brasília: MPA, 2010. 128p.

BRASIL. Ministério da Pesca e Aquicultura. Boletim estatístico da pesca e aquicultura 2011. Brasília: MPA, 2011. 60p.

BRASIL. Ministério da Pesca e Aquicultura. Consumo de pescado no Brasil aumenta $\mathbf{2 3 , 7 \%}$ em dois anos. 2013. Disponível em: $<$ http://www.mpa.gov.br/index.php/imprensa/noticias/2226consumo-de-pescado-no-brasil-aumenta-237-em-dois-anos $>$. Acesso em: 18 out. 2013.

FOOD AND AGRICULTURE ORGANIZATION OF THE UNITED NATIONS. Food outlook: biannual report on global food markets. Rome: FAO, 2013. 134p.

FOOD AND AGRICULTURE ORGANIZATION OF THE UNITED NATIONS. The state of world fisheries and aquaculture 2012. Rome: FAO, 2012. 209p.

SIDONIO, L.; CAVALCANTI, I.; CAPANEMA, L.; MORCH, R.; MAGALHÃES, G.; LIMA, J.; BURNS, V.; ALVES JÚNIOR, A.J.; MUNGIOLI, R. Panorama da aquicultura no Brasil: desafios e oportunidades. BNDES Setorial, v.35, p.421-463, 2012. 